\title{
ESCOLA BILÍNGUE E O PROCESSO DE APAGAMENTO DA LÍNGUA MATERNA
}

\author{
BILINGUAL SCHOOL AND THE MATERNAL LANGUAGE DELETION PROCESS
}

\author{
Paulo Augusto Mario Isaac \\ Universidade Federal de Mato Grosso (UFMT) \\ paulo-isaac@hotmail.com \\ Sílvia de Fátima Pilegi Rodrigues \\ Universidade Federal de Rondonópolis (UFR) \\ silviapilegi@gmail.com \\ Arcênio Bokodore \\ Escola Estadual Indígena Korogedo Páru \\ Escola Municipal Indígena Cadete Adugo Kuiare \\ arceniobokodore@gmail.com
}

\section{Resumo}

O objeto deste estudo é o relato de professores, estudantes e pais de alunos pertencentes à etnia Bóe-Bororo sobre o processo de apagamento da língua autóctone no âmbito da Comunidade localizada na Terra Indígena Tereza Cristina, no município de Santo Antônio de Leverger-MT. O objetivo é relatar as preocupações relativas ao apagamento da língua, na medida em que crianças e jovens permanecem mais tempo em contato com a língua portuguesa, dentro e fora do espaço escolar. Empregou-se o método etnográfico e foram analisados relatos de membros da Comunidade. Além do diálogo mantido com os colaboradores, solicitou-se que escrevessem um texto sobre a questão do ensino bilíngue na Comunidade Bóe-Bororo. Foram traçados paralelos entre aspectos da educação étnica e o espaço ocupado pela escola. Palavras-chave: Educação escolar indígena. Ensino bilíngue. Professor indígena. Bóe-Bororo. Língua materna.

\begin{abstract}
The object of this study is the accounts of teachers, students and parents of students belonging to the Bóe-Bororo ethnic group about the process of erasing the native language within the Community located in the Indigenous Territory Tereza Cristina, in the city of Santo Antônio de Leverger-MT. The aim is to report the concerns related to the delation process of the language, as children and young people have more contact with the Portuguese language, inside and outside the school environnment. It's been used the ethnographic method and reports from community members were analyzed. Besides the dialogue with employees, they were asked to write a text on the issue of bilingual education in the Bóe-Bororo Community. In addition to this, parallels were drawn between aspects of ethnic education and the space occupied by the school.
\end{abstract} Keywords: Indigenous school education. Bilingual teaching. Indigenous teacher. Bóe-Bororo. Mother language. 


\section{Introdução}

Este trabalho tem como objeto a reflexão sobre depoimentos de profissionais da Educação, estudantes e pais de alunos pertencentes à etnia Bóe-Bororo sobre a suposta ocorrência do apagamento da língua autóctone no âmbito da Comunidade localizada na Terra Indígena (T.I.) Tereza Cristina², município de Santo Antônio de Leverger - Mato Grosso. O foco de análise volta-se para o ensino bilíngue em duas escolas sediadas na Aldeia Korogedo Páru, na referida T.I., e a perspectiva de apagamento funda-se na afirmação, por parte dos indígenas ouvidos, de que a língua Bóe vem sendo substituída, paulatinamente, pela portuguesa.

Figura 1 - Mapa da Terra Indígena Tereza Cristina

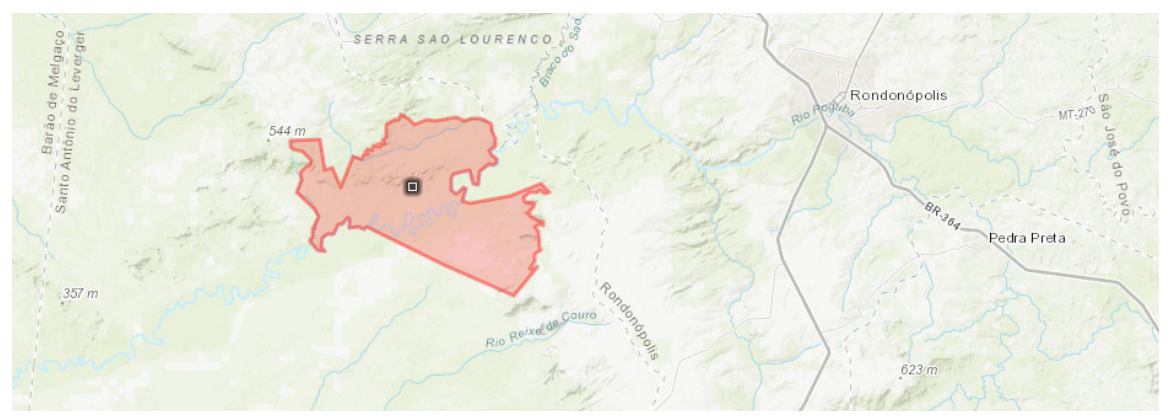

Fonte: Instituto Socioambiental (ISA). Disponível em https://terrasindigenas.org.br/pt-br/terras-indigenas/3870. Acesso em 24/01/2020.

Para iniciar o diálogo, importa destacar que os dois estabelecimentos de ensino aqui referidos dividem o mesmo prédio na Aldeia Indígena Korogedo Páru, em português Aldeia Indígena Córrego Grande, são elas: Escola Municipal Indígena Cadete Adugo Kuiare, que oferta os anos iniciais do Ensino Fundamental, e a Escola Estadual Indígena Korogedo Páru, com os anos finais do Ensino Fundamental e o Médio. Nas outras três aldeias, também situadas na T.I. Tereza Cristina, há salas anexas subordinadas administrativamente às escolas citadas.

Figura 2 - Vista aérea da Escola Estadual Indígena Korogedo Páru

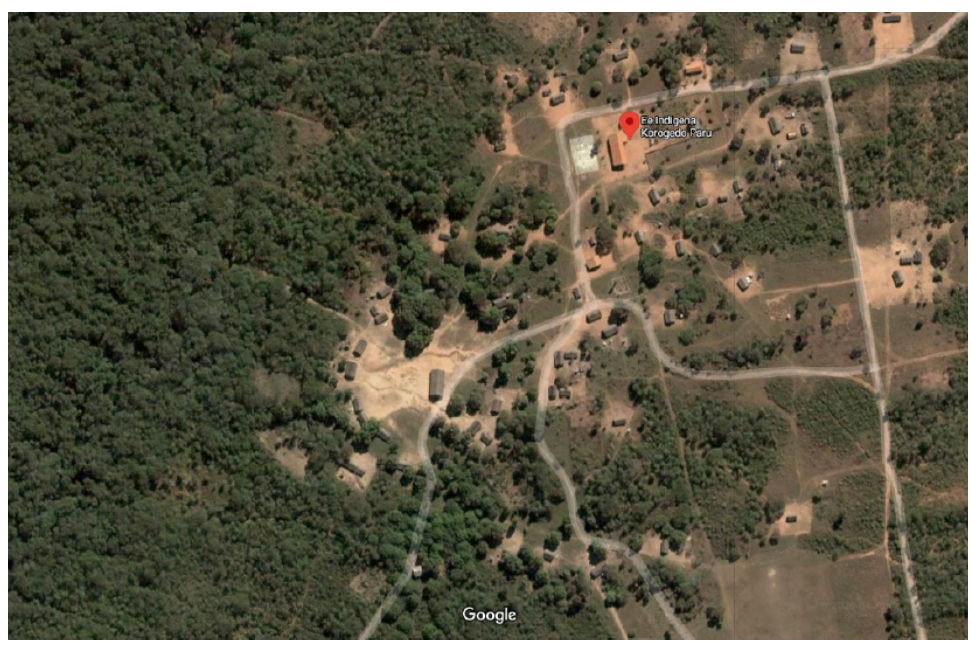

Fonte: Google Maps. Disponível em: https://www.google.com/maps/place/Ee+Indigena+Korogedo+Paru/@-16.5946313,-55.2148924,469m/data=!3m1!1e3!4m8!1m2!2m1!1sescola+ind\%C3\%ADgena!3m4!1s0x9378158997051c05:0xba84d3a31df0fc4f!8m2!3d-16.5934!4d-55.2139. Acesso em 24/02/2020.

1 Utilizou-se o binômio Bóe-Bororo porque Bóe é o termo pelo qual os membros dessa etnia se auto identificam, enquanto Bororo é a denominação que Ihes foi dada pelos colonizadores e com a qual ela ficou universalmente conhecida.

2 É conhecida também pela sociedade de contato do seu entorno e pelos próprios Bóe de outras localidades como "P.I. General Gomes Carneiro", em referência à antiga denominação do Posto Indígena do Serviço de Proteção aos Índios (SPI)/Fundação Nacional do Índio (FUNAI). A T.I. possui quatro aldeias. 
Segundo dados do Instituto Socioambiental (ISA), em 2019 essa T.I. possuía 506 (quinhentos e seis) habitantes, distribuídos em uma área de 34.149 (trinta e quatro mil, cento e quarenta e nove) hectares ${ }^{3}$.

Conforme dados levantados in loco na secretaria das escolas em análise, em 18 de novembro de 2019 elas atendiam a aproximadamente 196 (cento e noventa e seis) pessoas na faixa etária de 03 a 22 anos. Esse número é aproximado devido ao fato de que há mobilidade constante de famílias de uma terra indígena para outra, com entrada e saída de estudantes das escolas. No período correspondente à pré-alfabetização, 31 (trinta e uma) crianças eram atendidas e, nos anos iniciais do Ensino Fundamental, o número era de 58 (cinquenta e oito) estudantes. Os demais 107 (cento e sete) alunos distribuíam-se entre os anos finais do Fundamental e Ensino Médio.

Nesse contexto, a pedido de professores Bóe, o antropólogo Paulo Augusto Mario Isaac, um dos autores do presente artigo, iniciou em 05/09/2019 o Curso de Aperfeiçoamento para Professores Indígenas da E.E.I. Korogedo Páru e da E.I.M.E.B. Cadete Adugo Kuiare, ambas localizadas na Aldeia Korogedo Páru.

No primeiro diagnóstico realizado, os cursistas indicaram que a maior preocupação deles era a respeito da crescente preferência de crianças e jovens pelo uso da língua portuguesa em detrimento da Bóe-Bororo. Segundo eles, havia uma consciência dos Bóe de que o problema provinha das relações interétnicas da modernidade atual, na qual as escolas estavam inseridas. Em meio a essa situação colocou-se a problemática deste trabalho: o processo crescente de um suposto apagamento da língua materna no âmbito da Comunidade Korogedo Páru.

Nosso objetivo é descrever relatos de profissionais da Educação e outros membros daquela Comunidade, pertencentes à etnia Bóe-Bororo, sobre a suposta ocorrência do apagamento da língua materna, focalizando a participação da escola bilíngue nesse processo de modo a ponderar sobre alguns fatores que envolvem relações étnicas e interétnicas.

A hipótese inicial foi de que as crianças estavam entrando mais novas na escola, permanecendo maior tempo naquele espaço do que nos educacionais da cultura tradicional e acessavam, cada vez mais, as tecnologias eletrônicas, tais como televisão, rádios e telefones celulares. Nesse novo contexto, as pessoas indígenas passaram a necessitar mais da língua portuguesa como meio de comunicação e forma de interação com o mundo exterior à aldeia, do que a língua materna, que atende a uma demanda interativa interna da sociedade.

Durante os relatos iniciais dos profissionais da Educação, verificou-se que o suposto processo de apagamento da língua Bóe teria se iniciado na década de 1990, momento em que as políticas públicas do Estado brasileiro se voltaram para as etnias, sobretudo nas áreas da educação e da saúde. Anteriormente, as escolas indígenas estavam sob a responsabilidade do Serviço de Proteção aos Índios (SPI)/Fundação Nacional do Índio (FUNAI). A partir de 1980, a Aldeia Korogedo Páru recebeu uma professora missionária católica, a convite dos próprios índios, que trabalhou com eles durante 23 anos e implantou o ensino bilíngue na escola daquela Comunidade (ISAAC, 2018). Com a municipalização da educação escolar indígena, em 1991, foi criada a Escola Municipal Indígena Cadete Adugo Kuiare. O atendimento a outros níveis de ensino na própria Aldeia se deu a partir de 2005, quando foi criada a Escola Estadual Indígena Korogedo Páru.

A metodologia empregada nesta pesquisa foi a etnografia por meio da qual foi feita a coleta, o registro e a verificação dos dados relatados por 22 (vinte e dois) membros da Comunidade, sendo eles profissionais da Educação, discentes do Ensino Médio e pais de estudantes Bóe-Bororo. Para este artigo, foram selecionados depoimentos cuja amostra considerou pessoas de todos os clãs residentes na T.I. Tereza Cristina. As narrativas aqui expostas preservaram a identidade das pessoas, usando iniciais de seus nomes, acrescidas de números correspondentes às suas idades.

3 Disponível em https://terrasindigenas.org.br/pt-br/terras-indigenas/3870. Acesso em 15/01/2020. 
Além do diálogo mantido com os colaboradores, solicitou-se que eles escrevessem um texto a partir do título/tema "A questão do ensino bilíngue na Comunidade Bóe-Bororo". Para a produção escrita, de próprio punho, foi orientado que ela deveria conter introdução, desenvolvimento abordando o assunto proposto (situação social e impactos positivos e negativos) e conclusão do autor indicando os problemas em aberto para possíveis soluções.

Complementarmente, foram feitas anotações de depoimentos dados por eles em um painel, com o mesmo título dado à produção de texto, e ouvidos alguns moradores das aldeias da T.I. para confirmar se os dados coletados na Comunidade escolar se coadunavam com as impressões e preocupações da sociedade Bóe daquela localidade. Tendo verificado a universalidade da preocupação daquelas pessoas com o suposto processo de crescente apagamento da língua materna entre crianças e jovens no âmbito das suas aldeias, procedeu-se à tabulação dos dados e à análise da situação.

Para o desenvolvimento da análise foi considerado o contexto intercultural e socioambiental em que a problemática deste trabalho está inserida. Neste sentido, a referência bibliográfica pautou-se em autores que estudaram a educação escolar naquela Comunidade ou em outras T.I. Bóe-Bororo e que refletiram em Korogedo Páru, tais como Mendonça (2009), Isaac (2004; 2018), Isaac e Rodrigues (2017).

Com esta discussão, pretende-se contribuir para que a sociedade Bóe-Bororo e as agências de contato utilizem seus dados e reflexões para encontrar caminhos que favoreçam agregações culturais equilibradas, sem provocar perdas irreparáveis, tal como o apagamento da língua tradicional.

\section{A educação tradicional Bóe-Bororo}

Para compreender o processo de mudança social envolvendo a tensão entre os usos das línguas materna e portuguesa, é necessário conhecer alguns elementos que envolvem a educação tradicional dessa etnia. Até o momento da pesquisa, ela se processava fundamentalmente em cinco espaços socioculturais: bái muga, bororo, bái mána gejéwu, habitat tradicional e campo das relações interétnicas.

Bái muga - literalmente quer dizer casa da mãe. É o lugar onde a língua autóctone tradicionalmente tem primazia. É nesse espaço familiar que se dá primordialmente a formação pessoal, social e cultural Bóe-Bororo. Em seu contexto espacial, cada clã tem um lugar específico no universo (representado pelo círculo) da sua aldeia. As unidades familiares de cada clã edificam as suas casas em seu espaço clânico. Nele, as gerações mais novas são educadas de acordo com os valores e pertencimentos socioambientais que formam a sua identidade, bem como aprendem os comportamentos e obrigações socioculturais que lhes são devidos.

Figura 3 - Bái muga - Modelo de habitação Bóe-Bororo
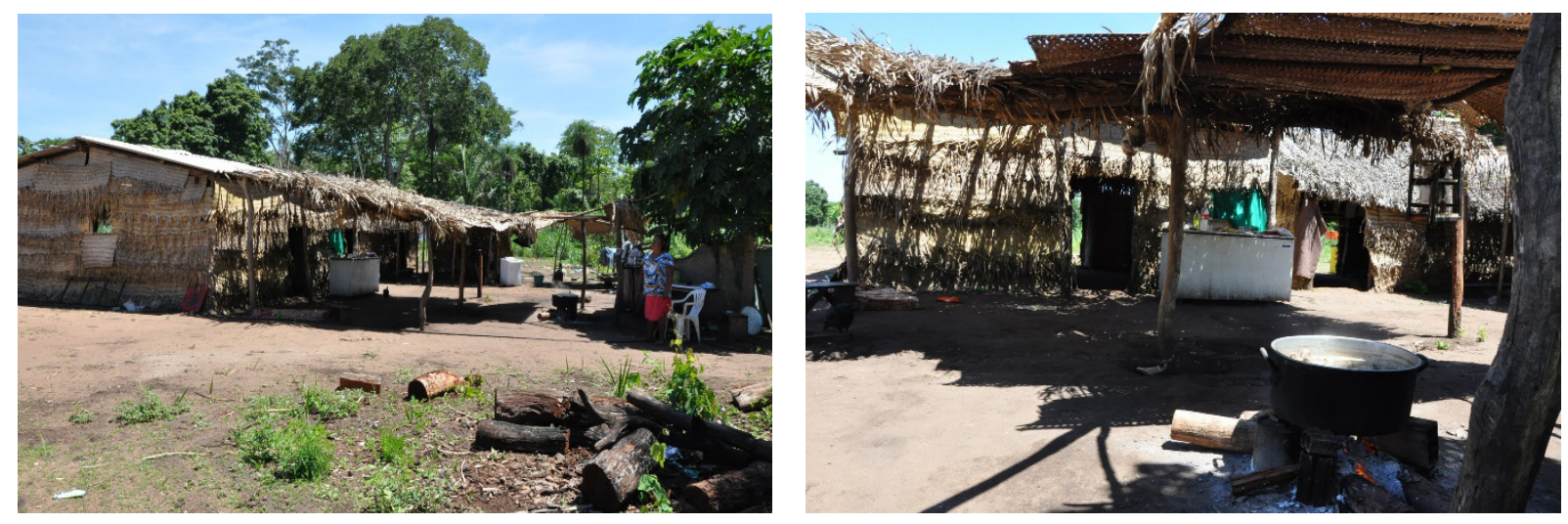

Fonte: Acervo de Paulo A. M. Isaac (23/03/2014) 
Cada habitação tradicional possui basicamente dois compartimentos separados: um ambiente fechado (para dormir, guardar pertences pessoais, de vivências íntimas e de cunho religioso) e outro externo (uma cobertura com as lateais parcialmente abertas onde funciona a cozinha e uma ampla área na qual as pessoas interagem). Deste modo, as crianças podem ser observadas, corrigidas e instruídas pelos adultos enquanto brincam no terreno do entorno.

Bororo - é o pátio central da aldeia em cujo círculo se localizam as habitações, cada qual em seu lugar clânico. A educação e a língua tradicionais são desenvolvidas também nesse espaço onde as pessoas interagem, realizam jogos, danças, cantos, eventos sociais, culturais e religiosos.

Figura 4 - Aldeia Korogedo Páru - marcação das casas em círculo

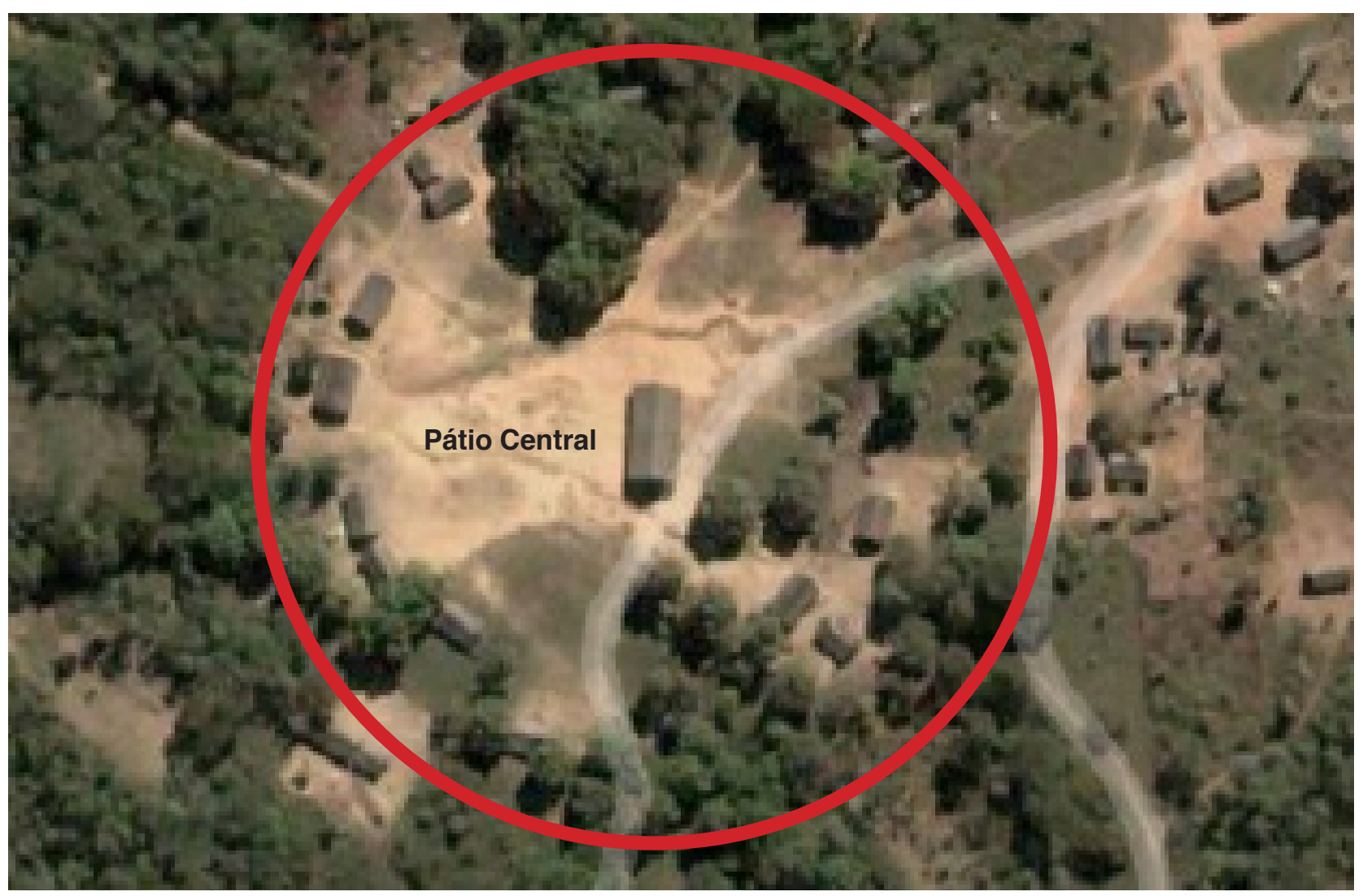

Fonte: Trabalho sobre imagem extraída de Google Maps. Disponível em: https://www.google.com/maps/place/ Ee+Indigena+Korogedo+Paru/@-16.5946313,-55.2148924,469m/data=!3m1!1e3!4m8!1m2!2m1!1 sescola+ind\%C3\%ADgena!3m4!1s0x9378158997051c05:0xba84d3a31df0fc4f!8m2!3d-16.5934!4d-55.2139. Acesso em 24/02/2020.

Há várias cerimônias que são realizadas no bororo, dentre elas se destaca o funeral, denominado Itaga ${ }^{4}$. Assim como outros espaços tradicionais dessa etnia, o bororo não é um lugar isolado ou independente dos outros. As crianças participam, junto com os adultos, dos eventos (respeitando-se as interdições pontuais) e, dessa forma, aprendem fazendo. A língua é um importante componente desse processo de aprendizagem na qual a oralidade e os gestuais corporais e instrumentais são as tradicionais formas de transmissão dos conhecimentos.

Bái mána gejéwu - também chamado báito pelos Bóe. Ele se localiza no centro do bororo. Os colonizadores o denominam, na literatura indigenista, "casa grande" ou "choupana central". Na verdade, ele é o templo sagrado dos Bóe-Bororo, espaço onde se realizam as cerimônias religiosas, rituais e eventos sociais tradicionais. É o lugar onde as gerações mais velhas praticam e ensinam os princípios, valores morais e éticos, crenças e comportamentos sociais para as gerações mais novas.

4 Mais detalhes sobre o funeral Bororo vide Albisetti e Venturelli (1962) e Isaac (2018). 
Figura 5 - Bororo com o báito ao centro

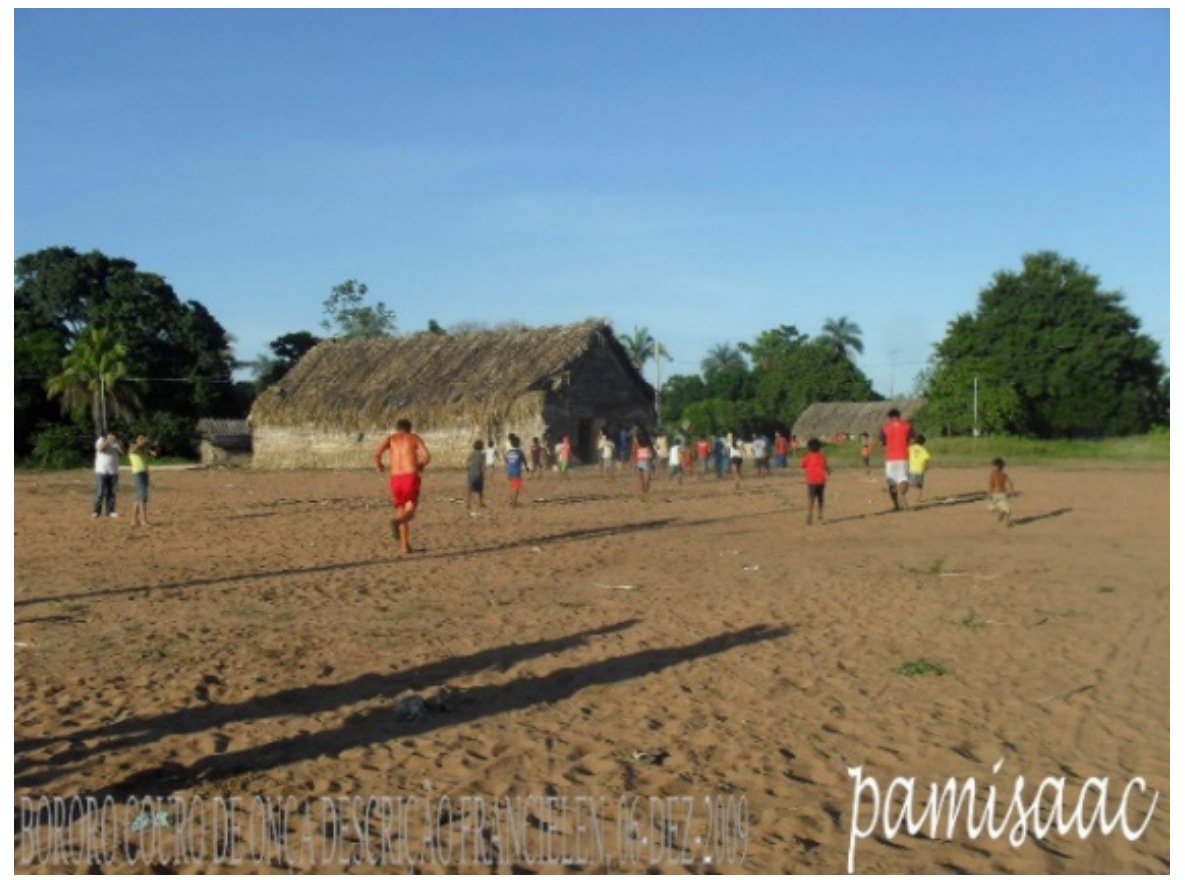

Fonte: Acervo de Paulo A. M. Isaac (23/03/2014)

Dentro do báito, os imédus (homens adultos) devem ensinar aos jovens os bakárus: histórias sagradas e todos os mitos de origem que compõem a sua cosmologia ancestral. Além disso, ensinam os diferentes significados das relações de trabalho nas quais, muitas vezes, as caças, pescas e coletas são restritivas, em função dos pertencimentos sagrados de alguns animais e plantas a clãs específicos e suas ligações com o mundo dos aróes (espíritos).

Figura 6 - Cerimônia do Funeral Bóe-Bororo realizada dentro do Bái mána gejéwu

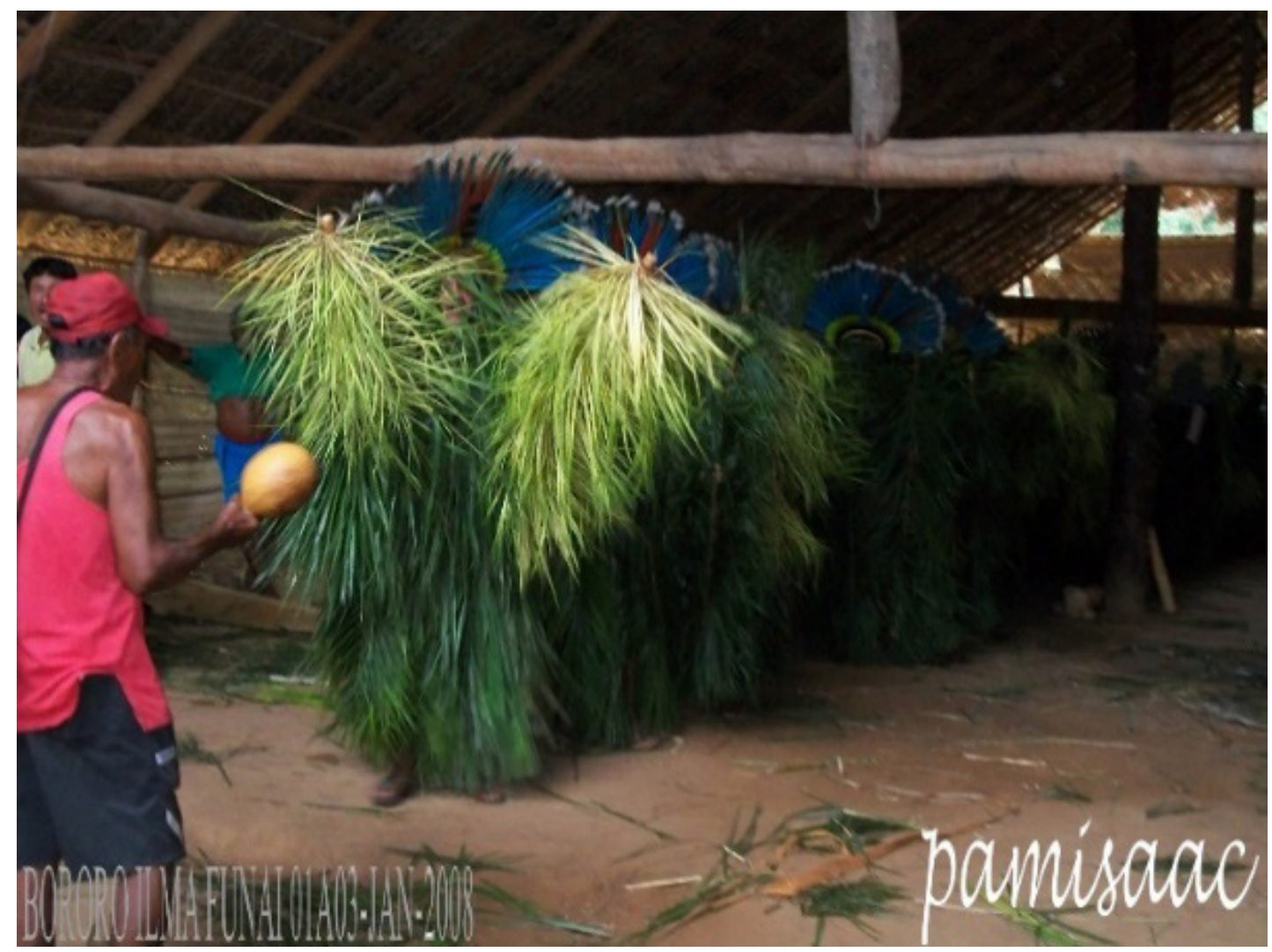

Fonte: Acervo de Hilma Chavier (03/01/2008) 
O bái muga, o bororo e o bái mána gejéwu são a arquitetura física e simbólica mais imediata da educação Bóe-Bororo, visto que nela se ensinam e aprendem, vivem e convivem todas as relações cosmológicas dessa etnia. Dentro do habitat tradicional, esses espaços são lugares consagrados da educação Bóe-Bororo e da sua tessitura social.

Habitat tradicional - é o ecossistema no qual as relações de produção da vida material e espiritual se manifestam: trabalho, educação, saúde, entretenimento, parentesco, religiosidade, línguas e linguagens. Nele os territórios físicos ganham significados, fazem sentido e se transformam em lugares históricos e sagrados, onde os outros três espaços étnicos acima mencionados se tornam palcos das representações da cosmologia Bóe-Bororo. O habitat tradicional é um lugar de sobrevivência material e espiritual.

Figura 7 - Vista aérea da Aldeia Korogedo Páru, T.I. Tereza Cristina

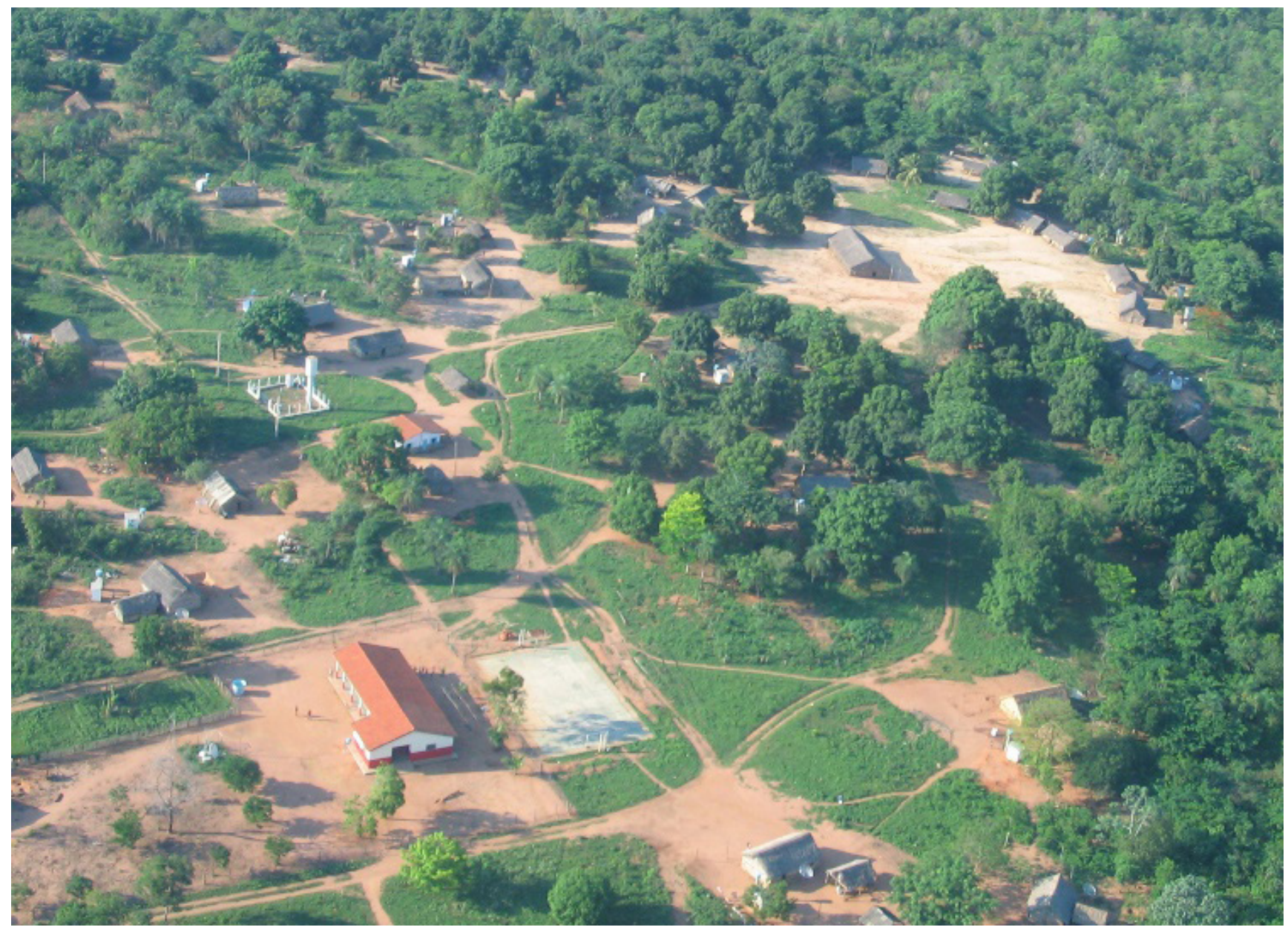

Fonte: Acervo de Mario Bordignon Enawuréu SDB (2005)

A T.I. Tereza Cristina se localiza no ecossistema Cerrado e seu principal rio é o São Lourenço, que desce para o Pantanal. É nesse ambiente onde se encontram que os seres ganham significados materiais e imateriais para essa etnia e ambos (seres e pessoas) se revestem de pertencimento mútuo. As constelações compõem essa natureza e fornecem conhecimentos e suportes para a compreensão dos ciclos do universo físico e da existência humana. Para os Bóe-Bororo, tudo na natureza é sagrado e forma uma teia de significados.

Campo das relações interétnicas - são lugares onde se operam as relações entre os Bóe-Bororo e os estrangeiros. Eles podem ser dentro ou fora da Terra Indígena. No aspecto físico das aldeias há a escola, o posto de saúde e o antigo posto da FUNAI. 
Figura 8 - Escola Korogedo Páru

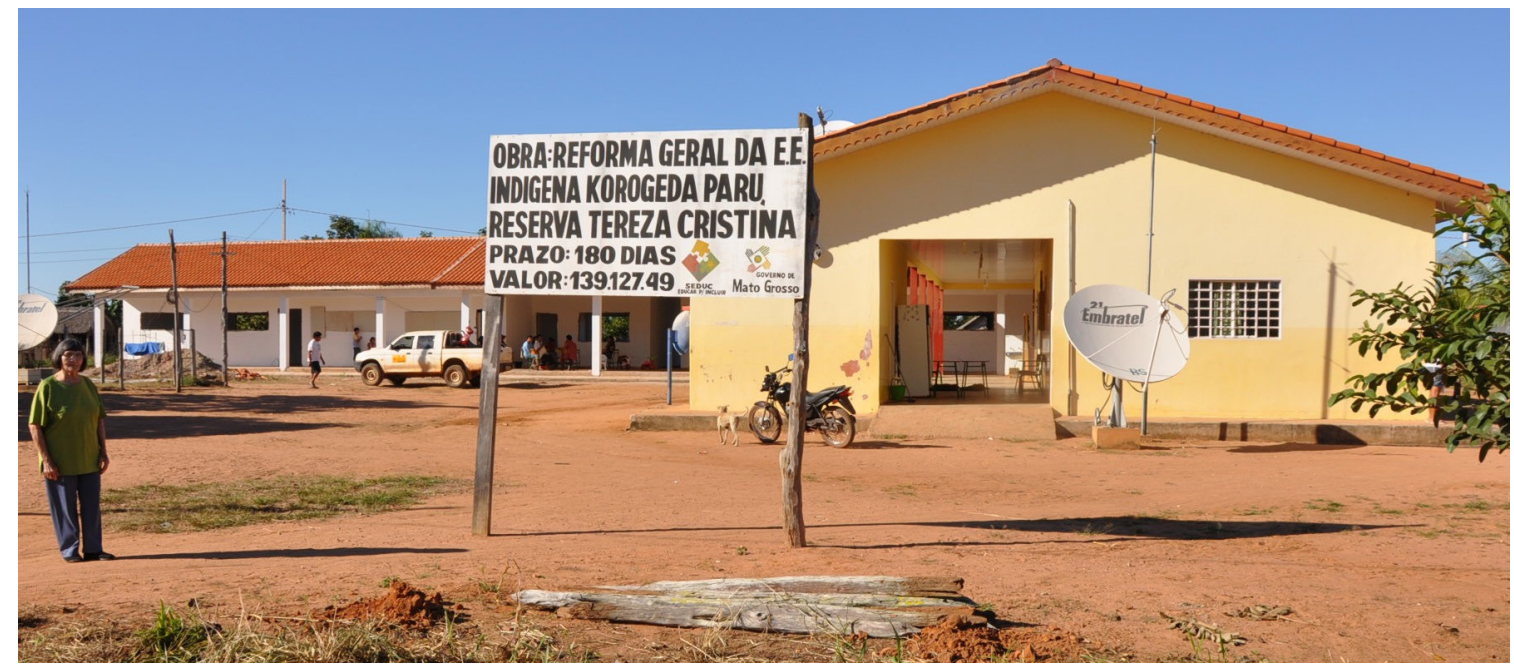

Fonte: Acervo Paulo A. M. Isaac (15/07/2012)

A escola indígena existe em Korogedo Páru desde o início da sua colonização (século XIX), mas começou a ser aceita pelos Bóe somente a partir da década de 1980. Este fato corrobora com as informações de Ferreira (1992) ao discutir sobre o movimento indígena ocorrido naquela década, na qual as etnias brasileiras desencadearam ações organizadas em favor da educação escolar nas aldeias. Ela escreveu que, "a partir da década de 1980, a finalidade das etnias passou a ser, eles próprios definirem e autogerirem seus processos de educação formal” (1992, p. 164).

No entanto, O processo de agregação da escola à vida da Comunidade de Korogedo Páru intensificou-se a partir de 1995, com a implantação, pelo Governo do Estado de Mato Grosso, do Projeto Tucum de Formação de Professores Indígenas em nível de Ensino Médio (ISAAC, 2004). Esse Projeto, patrocinado pelo Banco Mundial, desde a sua concepção, revelou seu caráter neocolonialista. Já no primeiro ano de sua execução, o Projeto Tucum manifestou a oposição de interesses entre índios e não índios envolvidos.

Programas como o Projeto Tucum apontam para as reais intenções do Estado quando se configuram como homogeneizadores, colonialistas e integracionistas, mas justificam-se pela necessidade e vontade que os povos indígenas envolvidos possuem em ter seus próprios professores. O projeto é o mesmo, mas a intenções e as estratégias dos agentes situados em campos diametralmente opostos são diferentes. (ISAAC, 1998, p. 68)

O bilinguismo se constituiu na primeira farsa a ser revelada pelo Projeto Tucum. O Polo I do curso (denominado Tangará da Serra) chegou a colocar na mesma turma oito etnias, ou seja, não era específico e nem bilíngue, a não ser no discurso que o justificava (ISAAC, 2002). A metodologia do Projeto Tucum foi centrada na estrutura da escola colonialista e transformou a cultura das sociedades indígenas em meros objetos de estudo. Atualmente, aquela mesma concepção permeia a estrutura administrativa, a organização curricular, didática e pedagógica da educação escolar indígena implantada no Estado de Mato Grosso. As autoridades educacionais colonizadoras discursam em favor do bilinguismo, mas na prática a língua materna é apenas uma disciplina escolar. Definir e autogerir seus processos de educação escolar formal é um desafio que os Bóe-Bororo enfrentam porque a escola continua no campo das relações onde o Estado brasileiro subordina as etnias aos modelos escolares burocráticos e homogeneizadores do nacionalismo republicano, que nega o pluralismo social dos povos que vivem no Brasil. 
Até a década de 1990, os conhecimentos autóctones eram transmitidos principalmente por meio da oralidade e outros processos da educação tradicional Bóe-Bororo, conforme já foi discutido neste artigo. A partir de então, a educação escolar foi ampliando a sua função dentro da Comunidade. A escola alterou não só as formas de apropriação do saber, como também ampliou as possibilidades de saberes. A oralidade vem perdendo a primazia na forma de transmitir os conhecimentos e os jovens questionam o que eles realmente precisam saber. Existe uma tensão na Comunidade e o uso da língua materna é a principal preocupação da sociedade Bóe-Bororo.

\section{0 bilinguismo entre os Bóe-Bororo da T.I. Tereza Cristina}

Neste tópico são transcritos os relatos dos profissionais da educação, estudantes, pais de alunos e demais membros da Comunidade sobre suas preocupações e percepções com relação ao suposto apagamento da língua materna, focalizando o que eles acham da participação da escola no processo do bilinguismo. Os relatos aqui transcritos são densos e emblemáticos em termos históricos e de percepções quanto ao problema acima mencionado. Também foram descritas as propostas dos Bóe para solucionar o desequilíbrio que eles dizem existir, ou seja, a preferência das crianças e jovens pelo uso da língua portuguesa em detrimento da materna.

Os textos foram selecionados, completos ou parciais, tendo em vista aqueles que melhor representam a totalidade do que foi mencionado pelas pessoas ouvidas, evitando-se repetições desnecessárias. Contudo, tomou-se o cuidado de não perder as variáveis, mesmo que pouco citadas pelos relatores.

$\mathrm{Na}$ totalidade das pessoas pesquisadas não houve quem não reconhecesse a importância do uso da língua portuguesa, nem quem se opusesse ao seu ensino na escola. Mas, a ênfase foi dada à necessidade de a escola, Comunidade e os órgãos governamentais ligados à Educação encontrarem meios para fortalecer a língua materna. Isso ficou bem explícito na redação de AB-26:

A Escola e a Comunidade estão em busca de soluções para melhoramento da linguagem interna Bóe e precisa do total apoio na formação dos nossos docentes da Intercultural ${ }^{5}$.

A Escola vem sendo a fonte de apropriação da língua portuguesa dentro da Comunidade Bóe. Os nossos professores ensinam os termos escolares mais na língua portuguesa e não conseguem traduzir os ensinamentos do português para a língua materna. Isso afeta muito as crianças, na atualidade.

Durante o painel de debates sobre o assunto, realizado no decorrer do Curso de Aperfeiçoamento para Professores Indígenas, em setembro de 2019, essa questão de não conseguir "traduzir os ensinamentos do português para a língua materna" foi debatida incluindo outras variáveis. A seguir são citadas três situações discutidas:

1) existem palavras em português que não têm tradução para a língua Bóe-Bororo; por exemplo: escola;

2) do mesmo modo do Bóe-Bororo para português; por exemplo: poguro (tradução aproximada de vergonha; sentir-se humilhado);

3) há palavras nas duas línguas que têm tradução, mas com significados diferentes, tais como mãe e muga. Em português mãe é a genitora de uma criança ou aquela que a cria. Muga é a genitora e todas as irmãs dela (tias maternas). Além disso, a palavra refere-se à lugar para morada e para assento.

5 Ele se refere aos cursos de formação de professores ministrados na Faculdade Indígena Intercultural, da UNEMAT - Universidade Estadual de Mato Grosso, Campus de Barra do Bugres. 
Dentre as questões discutidas surgiram questionamentos sobre o que deveria ser feito quando não há palavras equivalentes em termos de significado para se fazer a tradução. Deve-se usar o termo em português, no meio da fala em Bóe-Bororo, ou criar uma palavra nova na língua materna? Outro problema mencionado foi o fato de o alfabeto Bóe possuir 17 (dezessete) letras e o português 26 (vinte e seis). Alguns acentos, tal como o caron (`), que é essencial para a distinção fonética de algumas sílabas, sequer existem na língua portuguesa; por exemplo: Čibaíbo (lê-se Txibaíbo, que significa arara vermelha). A complexidade dessas diferenças gramaticais, linguísticas e semânticas não são conhecimento teórico dos professores indígenas, o que levou AB-26 a incluir a Faculdade Intercultural Indígena da UNEMAT, formadora dos professores indígenas, como corresponsável na solução das questões relacionadas ao bilinguismo interétnico.

Não é por acaso que a Comunidade se sinta confusa diante da situação social que eles estão vivendo atualmente. E, na procura por uma solução, as pessoas tendem a buscar as suas razões no processo histórico. O relato abaixo, de BPJB-44, é interessante por se tratar de alguém experiente na prática da educação escolar indígena e que tem vivenciado esse processo desde 1996. Veja o que ele disse:

Há três décadas não existia dificuldades com o ensino bilíngue porque a comunicação da sociedade dentro da Aldeia era expressa na língua materna.

Na atualidade, o impacto maior dos colonizadores foi a chegada das transformações tecnológicas na aldeia, como a energia elétrica [2003], o uso de materiais eletrônicos como os televisores e celulares. Isso levou a uma grande perda de nossas práticas culturais, principalmente a língua materna.

Portanto, o ensino bilingue hoje na escola poderia estar somente para ensinar as crianças a aprender a ler e escrever a língua materna. Mas, infelizmente não é assim. A escola está servindo como base para ensinar as crianças a falarem a língua materna, tarefa que deveria ser dos pais, dos familiares, das casas. (BPJB-44)

Inicialmente, BPJB-44 demarcou o tempo em que teria se acentuado o processo de alteração do uso da língua na comunicação dos Bóe de Korogedo Páru. Observe-se que ele fez referência a dois tempos: "há três décadas" e na "atualidade". Ele nos mostra que os fatores de mudanças no uso preferencial da língua não estão relacionados somente à escola, mas também a outros: tecnológicos e socioeconômicos provocados pelo contato interétnico. E, na última frase, ele aponta para o fato sociológico da transferência da função social do ensino língua materna. A Comunidade, gradativamente, está passando da responsabilidade da família para a escola. Então, BPJB-44 propõe uma reflexão ampliada sobre o problema:

Por tudo isso é preciso refletir com a comunidade e os pais como um todo o essencial sobre a língua materna e práticas culturais que estão sendo preservadas, para não ser abandonada sob a perda da identidade étnica. A fim de buscarmos a felicidade e aprender nos defender dos malefícios da sociedade envolvente. (BPJB-44)

Um outro relato, de VMC-22, reforça o posicionamento do autor acima descrito. Ele diz:

Atualmente os Bororo estão deixando de falar a sua própria língua porque no passado os adultos e as crianças davam mais importância para a sua cultura e a sua língua e acreditavam muito nas falas dos anciãos e do bári (xamã). 
No passar do tempo os Bororo foram deixando seus costumes, por exemplo, o de habitar as casas em seus espaços clânicos, o modo de falar e de se vestir no dia-a-dia.

Desse modo, as crianças não se comunicam mais na língua materna. É preciso mudar o modo de se comunicar com as crianças, usar menos o português e usar mais a própria língua. (VMC-22)

A cada relato percebe-se uma ampliação dos impactos da modernidade nas relações étnicas Bóe e a consciência da Comunidade em relação a eles. AB-26, lançou mão da narrativa de Outros (as pessoas mais velhas do seu clã) para explicar o que ele mesmo chamou de "processo de decadência da língua materna".

Os anciãos dizem que isso está acontecendo porque os Bóe mais novos não buscaram conhecer os significados dos cantos e remédios tradicionais e os regimes criados dentro da cultura Bóe introduzidos por eles, pelos bári e líderes fortes da cultura Bóe nos modos de antigamente.

Os jovens estão se apropriando mais da língua portuguesa e alimentando-se dela do que da língua da sua naturalidade. (AB-26)

Do ponto de vista antropológico, o relato soa como uma reclamação e um alerta dos mais veIhos sobre a perda, deles próprios, do poder de transmissão às gerações mais novas dos saberes da cosmologia daquela sociedade. Isto é motivo de preocupação, sobretudo considerando-se que a tradição oral é o principal modo pelo qual tais saberes são transmitidos e conservados. Assim, é compreensível que a questão do desinteresse dos jovens pelos "significados dos cantos e remédios", dita pelos anciãos, desenvolva neles o sentimento de negação da própria identidade étnica por parte das novas gerações. A agregação de uma língua estrangeira à sociedade Bóe tornando-a, por eles mesmos, primeira língua, não poderia deixar de causar tensões geracionais e crises existenciais em seus membros.

Sobre esse assunto, Isaac e Rodrigues (2017) analisam os impactos provocados pelas políticas públicas voltadas para a educação escolar indígena do Estado de Mato Grosso nas estruturas de sociedades específicas, tendo como foco os Bóe-Bororo, e ponderam que, dentre outros processos de mudança cultural, a constituição da escola como centro de transmissão de valores da sociedade universal recrudesce o consequente fortalecimento de lideranças jovens em detrimento de organizações tradicionais referentes às relações políticas e de parentesco. O que corrobora com a tensão de gerações expressa pelos anciãos que culpam os mais novos por não buscar os conhecimentos tradicionais, como argumenta AB-26, manifestando um sentimento de perda da própria identidade social e de impotência diante da inexorabilidade da mudança social em curso.

Os depoimentos expressam sentimentos de perdas, angústias, insegurança em relação ao futuro, medo de perder a identidade e territórios físicos e simbólicos, tristeza e impotência diante da implacabilidade das mudanças ocorridas, que estão acontecendo em ritmo diferente daquele que até então era experenciado pelos Bóe-Bororo. Antes, o ritmo da vida era percebido como mais lento e seguia o tempo da natureza. Atualmente, é acelerado e os jovens dizem querer e precisar adequar-se aos moldes da mundialização das tecnologias. É sabido que as mudanças sociais são mais lentas do que os avanços tecnológicos e, ao que tudo indica, a língua Bóe lhes parece insuficiente para compreender o mundo no qual eles pretendem ter uma participação mais ativa e inclusiva e chamam de "futuro". O relato de $\mathrm{Cl}-25$ expressa alguns desses sentimentos de modo dramático: 
O ensino bilíngue está sendo visualizado como mais um dos problemas que estamos enfrentando com muita preocupação e desespero. Porque as novas gerações da sociedade Bóe-Bororo não querem falar a língua materna sendo a nossa identidade Bóe-Bororo.

O meu ponto de vista a geração Bóe da minha aldeia estão tendo muita dificuldade na língua materna, porque eles não falam no seu dia-a-dia, as crianças não conseguem identificar os nomes de animais, peixes, aves e até mesmo palavras Bóe-Bororo, com essa dificuldade leva a criança ter vergonha de conversar com os mais velhos. Eles não conseguem identificar seu clã e as suas pinturas faciais e corporais. Então está sendo um dos mais preocupantes problemas que estamos enfrentando.

Na minha opinião, a sociedade Bóe-Bororo tem um ponto referencial que é a escola, mas os ensinos Bóe-Bororo partem primeiro dos pais, da família; a escola, como se diz, é para complementar a educação. No entanto, a escola está sendo um ponto de referência quando toca nesse assunto porque as crianças são alfabetizadas na escola e justamente na escola. (Cl-25)

Como se pode ver até agora, as preocupações com as mudanças em curso na Comunidade não se reduzem à língua e à cultura abordadas de um modo genérico. Os depoentes remetem a questões práticas, dividem as responsabilidades entre todos os segmentos e, a cada relato, apresentam novas perspectivas de análise. Observe-se que há um sentimento de insegurança e confusão com uma suposta desordem pelo fato de a educação não estar sendo processada a contento - na perspectiva de depoentes - nem no âmbito institucional tradicional e nem na escola, que se acredita ser uma alternativa para manter os valores étnicos daquele povo. A escola não está ocupando o espaço de poder dos anciãos e, em momento de crise, ela própria reflete a crise de poder que existe na Comunidade. As acusações sobre comportamentos socialmente condenáveis de autoridades escolares são percepções de que elas não têm legitimidade institucional, conhecimentos e posturas pessoais para assumirem o poder político educacional inter e intracultural.

Nós estamos muito preocupados com os nossos filhos. Ele tem muita dificuldade de ler, por isso que tem vergonha de ir à escola [..]. [O professor] fala com ele, que nem sabe nada! Quando eu estudava nessa escola, não eram assim. O professor respeitava muito o diretor e a secretária, mas hoje nem respeita. O professor nem dá atenção pra dar aula. Aqui nessa aldeia Córrego Grande, nós temos a cultura, mas falta o interesse porque nem o pai, a mãe nem fala em língua materna, fala só língua portuguesa. Mais idosa, idoso que conta e chora, fala com a língua materna, e fala com os filhos, mas nem obedecem. Hoje mudou. Hoje existe futebol, nos enfocam muito nisso. Também mudou muita coisa. Hoje tem até internet é também tem celular. A comunidade quer os filhos falando a língua materna. Antigamente sabia tudo o remédio do mato, ensinava pra passar para melhorar, para ter a sua inteligência. O diretor foi na escola bêbado. As crianças têm muito medo de ir à escola. Aí os professores acompanham, nem respeitam o diretor. Esse ano nem tem aula direito pra criança. O professor falta muito. (SN-35)

Esse depoimento revela a contradição vivida pela sociedade Bóe ao depositar suas expectativas na escola como espaço de resistência aos impactos colonizadores e se depara, no ambiente escolar, com os mesmos problemas e dilemas vividos na Comunidade. Essa relação dialética é compreensível do ponto de vista antropológico, sobretudo se considerar que até a primeira década do séc. XXI as comunidades daquela etnia colocavam a educação escolar como "coisa de branco". Agora ela está inserida na vida comunitária e engendra as suas contradições, ou seja, tornou-se problema da etnia. 
Em 1996, Isaac escreveu o seguinte:

É preciso considerar, pois, que o poder não se institui a partir das relações de contato, e sim no sistema social Bóe-Bororo.

Por isso, quando as tensões se acirram, a força que mantém a unidade da Comunidade vem do campo da estrutura sociopolítica tradicional, onde os parentes, idosos e os clãs dos maiorais têm realmente poder de decisão.

É conforme diz o cacique Avelino Macaw: No final, quem tem que resolver é nós da cultural. (ISAAC, 2004, p. 61)

Deste modo, os problemas das mudanças culturais atuais deveriam, em tese, ser resolvidos nos parâmetros da estrutura sociopolítica tradicional, mas não somente por ela, porque a escola também se constituiu em um espaço de difusão da educação tradicional e, portanto, de poder étnico.

Na minha Comunidade Bóe-Bororo, por volta de 1982, a língua Bororo tradicionalmente era riquíssima. Os nossos pais e os nossos tios e padrinhos tinham grande conhecimento sobre a nossa língua materna. Eles tiveram esse conhecimento através dos conselhos dos mais velhos, com os xamãs e com as mães. Nesse caso, a estrutura da nossa língua Bororo foi passada para os infantis e jovens por meio de conselhos. Por isso, naquela época as crianças tinham uma finalidade fácil na língua materna.

Antigamente as pessoas só dialogavam na língua Bóe e isso propiciou que os pequeninos crescessem conhecendo a nossa língua materna e a nossa cultura tradicional.

No ano de 2007 em diante, nós tivemos uma grande dificuldade com a nossa língua Bororo. Surgiram novas tecnologias como a televisão, micro-sistem, celular etc. Por isso os infantis e os jovens têm dificuldade de falar a língua Bóe-Bororo. Essa tecnologia é toda falada em língua portuguesa, fato que contribuiu para os jovens incorporarem rapidamente a língua portuguesa e nos traz uma imensa dificuldade de falar a língua Bororo.

Os pais não aconselham os filhos a falarem na língua Bororo. Por isso, aqui dentro da Aldeia Korogedo Páru, na nossa escola, temos que ter um professor de língua Bororo para ensinar os alunos da creche e Educação Infantil e outros.

É necessário estudar a língua Bóe-Bororo na nossa estrutura tradicional e o que está sendo incorporado e criado com o contato e as novas tecnologias. (FB-28)

Este relato, além de tratar a situação social demarcando-a temporalmente e fazer abordagens sobre alguns impactos, trouxe como novidade dois aspectos que merecem considerações: a finalidade que as pessoas têm em aprender uma língua e a minimização do impacto da escola no uso crescente da língua portuguesa pelos jovens. Esses dois aspectos serão tratados a partir de agora.

Já foi observado que os adultos dão importância à língua materna porque ela é o meio de comunicação pelo qual os saberes Bóe-Bororo são transmitidos e apreendidos pelos membros da etnia. Note-se que os jovens atribuem utilidades à língua portuguesa e, em decorrência delas, vislumbram novas as perspectivas de futuro. RCK-28 assim descreveu:

Na nossa Comunidade aprendemos a falar as duas línguas, a Bóe e a portuguesa.

Hoje em dia, os alunos se expressam mais saber o português, tanto as crianças como os jovens. Alguns sabem a língua materna, mas não falam porque têm vergonha, por isso os educadores têm que ficar mais atentos para que eles falem a língua Bóe dentro da sala de aula. Os professores têm que fazer pegar costume de falar e entender os significados da nossa cultura. Mas, está muito difícil ver eles falando a própria língua materna, muitos quase não entendem bem a nossa língua. 
A escola deve dar um bom ensino para os alunos, ensinar o português e a língua materna, as duas para serem faladas e escritas. Assim as pessoas não vão ter dificuldade de falar com as autoridades, por isso temos que priorizar as duas línguas. Não podemos esquecer de falar sempre a língua do nosso povo Bóe-Bororo, que é a nossa língua. (RCK-28 - grifos nossos)

Como é possível observar, RCK-28 atribui à escola o dever de "dar um bom ensino para os alunos", que consistiria em ensinar o português e a língua materna, "as duas para serem faladas e escritas" com o propósito de que isso facilite a comunicação com as autoridades da sociedade de contato. Ressalte-se que, embora ele mencione a importância de não se esquecer a língua materna, a própria conservação e transmissão é colocada como função da escola. O próximo relato, de LPI-26, também destaca a necessidade do domínio das duas línguas.

O ensino bilíngue na nossa comunidade está sendo muito importante para as nossas crianças sim, na escola, porque assim quando eles crescer não vão ter dificuldade de conversar com os brancos, principalmente quando for prestar um vestibular. [...]

Mas também no meu ponto de vista não é legal só ensinar a língua portuguesa, porque a nossa língua é nossa identidade, porque se a gente não falar a língua materna, nós corremos grande risco futuramente, principalmente de perder a nossa terra. Essa é a minha grande preocupação hoje, porque atualmente nós estamos sendo iguais aos brancos, principalmente as casas de hoje não estão mais como de antigamente.

Tudo isso que vem acontecendo hoje e em dia o que eu mais quero é que as duas línguas andem juntas, assim que tem que ser, mas tem que vir da nossa comunidade, porque precisamos das duas línguas. (LPI-26)

LPI-26 expressa com clareza o seu desejo de que "as duas línguas andem juntas" como forma sanar as dificuldades das novas gerações, com destaque para o avanço nos estudos em níveis superiores aos ofertados na aldeia. O jovem LBB-25 também vê no bilinguismo a oportunidade de estudar em uma faculdade, sem renunciar a sua cultura e identidade.

Na escola nós aprendemos as duas línguas: materna e o português. Nós precisamos aprender as duas línguas porque a materna é a nossa cultura e a nossa identidade e a língua portuguesa porque nós vamos entrar numa faculdade dos não indígenas e temos que falar bem o português. (LBB-25)

Em outra direção, o mais jovem dos depoentes, GKE-15, explicita contradições não reveladas por RCK-28, LPI-26 e LBB-25:

Antigamente era tudo diferente, as crianças só falavam a língua materna porque não existia branco. De uns tempos para cá, começou a mudar, tem professor indígena, os próprios pais falam só a língua portuguesa.

Agora, as crianças e os jovens só falam o português porque nós esperamos que as coisas mudem para o nosso futuro. (GKE-15 - grifos nossos)

Compreende-se que, embora não haja uma conotação de crítica, GKE-15 expressa que as "crianças e os jovens só falam o português" porque esperam que "as coisas mudem para o [...] futuro" deles, e os "próprios pais falam só a língua portuguesa". Ou seja, ele não percebe o bilinguismo da mesma forma que os demais, ao contrário, sequer nota a presença de falantes da língua materna entre crianças e jovens, o que é visto por GKE-15 como uma possibilidade de futuro promissor. 
Nos depoimentos de GKE-15, SN-35, Cl-25 e BPJB-44 é perceptível o quanto a língua portuguesa vem ganhando primazia na aldeia, em detrimento da língua materna, isto porque a primeira é valoriza a partir dos benefícios (diretos e/ou indiretos) que oportuniza na relação de contato, como a interação com os não indígenas, o acesso ao Ensino Superior e, consequentemente, a postos de trabalhos até então inexistentes na sociedade Bóe, além de outras questões de cunho financeiro, social, político.

Para a maior parte dos depoentes, os impactos negativos são identificados como movimento de substituição da língua Bóe pela portuguesa. Já foi dito que a Comunidade não tem encontrado mecanismos para lidar com essa situação, daí a sensação de que há um desprezo de muitas pessoas - crianças e jovens - para com as autoridades tradicionais. Este fato é perceptível a partir, por exemplo, da ausência de muitos jovens em reuniões com anciãos, chefes de clãs e representantes de segmentos sociais que atuam no ambiente social Bóe-Bororo; em detrimento da participação em eventos cerimoniais, percebe-se preferência pelo futebol, por exemplo. Além disso, com as políticas públicas a respeito da educação escolar indígena, os professores ganharam maior prestígio que os anciãos junto aos colonizadores, fato que talvez tenha perturbado as relações de poder internas, assunto esse tratado por Isaac e Rodrigues (2017). Ao mesmo tempo, como pode ser exposto nos depoimentos dos mais jovens, eles estão vislumbrando profissões e ocupações inexistentes até a década de 1990 na aldeia e que, no contexto das relações de contato atuais, parecem ser mais vantajosas para eles, tais como professores, agentes de saúde, motoristas, biólogos, médicos, advogados e outras ${ }^{6}$. Segundo os depoentes, tais ocupações poderão ser agregadas para o trabalho na própria Terra Indígena ou fora dela.

\section{Considerações Finais}

Os relatos e os debates ocorridos sobre a escola bilíngue e o processo de apagamento da língua autóctone revelaram que a realidade em torno do bilinguismo na T.I. Tereza Cristina extrapola o âmbito da escola. Ela é um elemento da totalidade social na qual estão imbricadas tanto as relações étnicas quanto as interétnicas.

A preocupação com o uso cada vez maior da língua portuguesa em detrimento da materna não é uma oposição dos moradores ao uso da língua colonizadora e sim com o fato de que várias mudanças sociais e culturais estão ocorrendo ao mesmo tempo. A língua também é um fator de mudança e está afetando a aprendizagem e uso da Bóe-Bororo.

Contraditoriamente, embora a escola seja reconhecida como um meio de propulsão da língua portuguesa, ela tem se constituído, na perspectiva de membros da Comunidade, como uma forma de resistência da cultura autóctone, na medida em que ensina e exige das crianças e jovens o uso da língua materna. Neste sentido, vários desafios se colocam, principalmente no processo de alfabetização das crianças no contexto escolar. Dentre esses, podemos destacar: 1) a estrutura curricular, que segue as diretrizes da sociedade abrangente; 2) os materiais didáticos, majoritariamente na língua portuguesa e elaborados com vistas à sociedade não indígena, classe média e urbana; 3) o fato, relatado aqui por alguns depoentes, de que nem os professores sabem/usam a língua materna na escola.

6 Já existem jovens da T.I. Merúri cursando Medicina, Geografia e Biologia e formados em Enfermagem, além de uma jovem de Tereza Cristina estudando Pedagogia na UFMT. Este fato certamente tem influenciado as gerações mais novas das terras indígenas Bóe-Bororo. 
A expectativa em relação à Educação escolar indígena bilíngue se dá por diversos motivos, mas o principal é que o eixo da educação das crianças Bóe-Bororo vem sendo deslocado, desde a década de 1990, dos espaços tradicionais para a escola, ou seja, para o campo das relações interétnicas. Entretanto, as exigências da Comunidade não são o apagamento da língua materna e nem a supressão do ensino da portuguesa. A maioria das pessoas quer um equilíbrio no uso das duas línguas, sem, contudo, que a materna perca seus fundamentos de significação, identidade e territorialidade física e simbólica. Pelo contrário, muitos relatos indicaram que os Bóe querem aprofundar o conhecimento da sua língua tradicional, tanto do ponto de vista da estrutura linguística quanto do conteúdo semântico. A língua portuguesa, por seu turno, é tida como um importante instrumento de poder e interação nas relações de contato com a sociedade globalizada. A questão, pois, não é tratada como se opor a ela e sim conhecê-la e agregá-la, sem perder a língua Bóe.

Neste sentido, a hipótese inicial era de que as crianças estavam entrando mais novas na escola, permanecendo maior tempo naquele espaço do que nos educacionais tradicionais e acessavam tecnologias eletrônicas de comunicação, tais como televisão, rádios e telefones celulares. Assim, a língua portuguesa tornou-se cada vez mais presente nas interações dentro e fora da aldeia, em detrimento da materna. Os relatos aqui apresentados e os demais dados reconhecem a existência desses fatos que, associados ao contato permanente com a população não índia do entorno da Terra Indígena, estão impactando fortemente o predomínio do uso da língua materna nas aldeias.

Contudo, segundo a própria Comunidade, a educação escolar indígena não está sendo o fator desencadeante desse processo. Ao invés disso, a escola tem se revelado como a principal resistência ao apagamento, uma vez que é sua política estratégica fortalecer o uso da língua materna. A escola, todavia, sofre as concorrências da estrutura escolar colonizadora imposta pela burocracia estatal e pelos avanços das tecnologias mundiais. Acrescentam-se a isso as mudanças ambientais, que criam relações de trabalho e necessidades de sobrevivência, e a pressão da sociedade do entorno por um relacionamento interétnico "moderno", o que implica em consumo de mercadorias até então desnecessárias à vida cotidiana daquele povo. Contraditoriamente, para levar os jovens a compreender o contexto social interétnico em que vivem, a escola reproduz o uso das línguas colonizadoras, na medida em que não encontram significados e significantes para traduzi-las e ressignificarem na cosmologia Bóe-Bororo. Este é, ao nosso ver e dos depoentes, o desafio atual da Comunidade Indígena de Korogedo Páru.

\section{Referências}

ALBISETTI, César; VENTURELLI, Angelo Jayme. Itága. In: ALBISETTI, César; VENTURELLI, Angelo Jayme. Enciclopédia Bororo vol. 1. Campo Grande, MS: Museu Regional Dom Bosco, 1962, p. 647-668.

ISA. Instituto Socioambiental. Terra Indígena Tereza Cristina. Disponível em https://terrasindigenas.org.br/pt-br/ terras-indigenas/3870. Acesso em 15/01/2020.

ISAAC, Paulo A. M. Autonomia e Autodeterminação: o novo discurso da diferente. Revista de Educação Pública. Cuiabá, EDUFMT, v. 7, $\mathrm{n}^{\circ}$ 12, jul/dez.1998, p. 59-72. Site: http://pauloisaac.com/livros_pdf/ e5cf275261356dfb474c6f395e6660de.pdf

ISAAC, Paulo A. M.. Formação de professores índios: um programa específico para os Bororo. Revista Busca e Movimento. Rondonópolis, UFMT/Depto. de Educação, ano 5, n 5, 2002, p. 87-102. Disponível em http:// pauloisaac.com/livros_pdf/8e5dace9d0a27dbf0b19eb22deb3b117.pdf. Acesso em 15/01/2020. 
ISAAC, Paulo A. M. Drama da Educação Escolar Indígena Bóe-Bororo. Cuiabá. EdUFMT, 2004.

ISAAC, Paulo A. M. Irmã Maria Čibaibo Ossemer - uma missionária franciscana entre os índios Bóe-Bororo de Mato Grosso. Cuiabá. EdUFMT/Carlini\&Caniato, 2018.

ISAAC, Paulo A. M. Modos de Existir Terena na Comunidade Multiétnica que vive em Mato Grosso. São Paulo. Tese de doutorado. Pontifícia Universidade Católica de São Paulo - PUC-SP/Programa de Pós-Graduação em Ciências Sociais, 2004. Disponível em http://pauloisaac.com/livros_pdf/e1d0541bda1d3d4e23bc269d7200e4bf. pdf. Acesso em 20/01/2020.

ISAAC, Paulo A. M.; RODRIGUES, Sílvia de Fátima Pilegi. Educação Escolar Indígena: impactos e novas formas de colonização. COCAR, Belém. V. 11, n. 22, p. 60-86, jul./dez. 2017. Disponível em file:///C:/Users/User/ Downloads/1597-4422-1-PB.pdf. Acesso em 24/01/2020.

FERREIRA, Mariana K. L. Da origem dos homens à conquista da escrita: um estudo sobre povos indígenas e educação escolar no Brasil. São Paulo, Dissertação de Mestrado P.P.G. em Antropologia Social da USP, 1992.

MENDONÇA, Terezinha F. Gestão Escolar Indígena - Interculturalidade e Protagonismo. In: Coletânea Educação Escolar Indígena. V. 6. Cuiabá, EDUFMT/SEDUC-MT, 2009.

Recebido em: 29/08/2019

Aceito em: 22/10/2019 